\title{
Characterization and in vitro degradation of poly(octadecanoic anhydride)
}

\author{
An-Jie Dong · Jin-Wei Zhang · Kai Jiang • \\ Lian-Dong Deng
}

Received: 31 January 2006/Accepted: 18 September 2006/Published online: 19 June 2007

(C) Springer Science+Business Media, LLC 2007

\begin{abstract}
Poly(octadecanoic anhydride) (POA) has been prepared by melt polycondensation of octadecanoic diacid. POA was characterized by Fourier-transform infrared spectroscopy (FTIR), differential scanning calorimetry (DSC) and wide angle X-ray diffraction (WAXD). The results of in vitro degradation and SEM micrographs show that the erosion process of POA is neither bulk nor perfect surface erosion but rather has elements of both in phosphate buffer at $37^{\circ} \mathrm{C}$. The moving erosion front is characteristic of surface erosion whereas the remaining porous shell stems from bulk erosion. While a significant special degradation property of POA is that POA presents a very slow degradation rate in acidic condition ( $\mathrm{pH}$ 5.98), only $1.64 \%$ weight loss for 20 days, and it completely degrades after 18 days in basic buffer (pH 7.4). Comparing with poly(sebacic anhydride) (PSA), POA has the higher crystallization degree, and the slower hydrolytic rate.
\end{abstract}

\section{Introduction}

Synthetic biodegradable polymers are attractive candidate materials for short-term medical applications, such as sutures, drug delivery devices, orthopedic fixation devices, wound dressings, temporary vascular grafts, different types of tissue engineered grafts, etc. [1-3]. The extensively investigated biodegradable polymers for controlled drug

A.-J. Dong · J.-W. Zhang · K. Jiang · L.-D. Deng ( $\bowtie)$ Department of Polymer Science and Technology, School of Chemical Engineering and Technology, Tianjin University, Tianjin 300072, China

e-mail: dengliandong@yahoo.com.cn delivery applications include polyesters, polyanhydrides, polycyanoacrylates, poly(amino acid), poly(ortho ester), polyphosphazenes, etc. [4].

Polyanhydrides are novel biodegradable polymers and their surface-eroding property in aqueous medium makes them desirable for drug controlled release and functional soft tissue substitutes [5, 6]. The first application of polyanhydrides as a bioerodable matrix for the controlled drug delivery systems was reported by Rosen et al. [7]. Since then, polyanhydrides of aliphatic and aromatic diacids have been extensively investigated as useful biomaterials for the controlled drug delivery systems $[8,9]$.

Hundreds of polyanhydrides have been synthesized in recent 20 years, such as aliphatic polyanhydrides, aromatic polyanhydrides, crosslinked polyanhydrides $[10,11]$, poly(ester anhydride) [12-14], poly(ether anhydride) [15, 16], aliphatic-aromatic polyanhydrides [17] and poly(amide anhydride) [18, 19], etc. Nevertheless only poly(sebacic anhydride) and its derivations are applied in the drug-controlled release system, including poly[(1,3$\operatorname{bis}(p$-carboxyphenoxy)propane)-co-(sebacic anhydride) (P(CPP-SA)) [20], poly[(1,6-bis-p-carboxyphenoxy hexane)-co-(sebacic anhydride)] (P(CPH-SA)) [21, 22], poly[(erucic acid dimer)-co-(sebacic anhydride)] (P(EADSA) $[23,24]$ and poly[(fumaric acid)-co-(sebacic anhydride)] (P(FA-SA)) [25, 26], etc. The Food and Drug Administration (FDA) has approved the use of $\mathrm{P}(\mathrm{CPP}-\mathrm{SA}$ ) to deliver the chemotherapeutic agent BCNU for the treatment of brain cancer [27]. The main advantages of the above polyanhydrides are as follows: (1) biodegradation and surface erosion; (2) adjustability of degradation rate and drug release rate; (3) approximate to near zero order drug release and no burst effect; (4) biocompatibility; (5) excellent stability of the drug-controlled release system composed of drug and polyanhydrides. 
As a kind of novel biomaterials for the drug-controlled release system, polyanhydrides are extensively used in the investigation of the controlled release system of anticancer agents [28-30], antibiotics [23, 30, 31], DNA [32], peptides and proteins $[33,34]$, etc. Though there are many advantages, biocompatible polyanhydrides have some limitations. For example, the hydrolytic instability of polyanhydride increases with the monomer chain length decreasing and the polyanhydride undergoes spontaneous depolymerization to low molecular weight polymers in organic solutions or during storage at room or higher temperatures.

According to the relationship of the hydrolytic instability with the monomer chain length, poly(octadecanoic anhydride) (POA) was synthesized by melt polycondensation of octadecanoic diacid, which is refined from the edible plant lipid. The properties of POA were characterized by Fourier-transform infrared spectroscopy (FTIR), differential scanning calorimetry (DSC) and wide angle X-ray diffraction (WAXD). The degradation behaviors in vitro of POA were also investigated.

\section{Experimental}

\section{Materials}

Octadecanoic diacid (99\%) was purchased from Kening (Shanghai, China) and recrystallized twice in ethanol. Acetic anhydride (99.5\%, Bodi, Tianjin, China), toluene (anhydrous, Kewei, Tianjin, China), ethyl ether (anhydrous, Damao, Tianjin, China), petroleum ether (anhydrous, Kewei, Tianjin, China), chloroform (anhydrous, Kewei, Tianjin, China) and tetrahydrofuran (anhydrous, Bodi, Tianjin, China) were all analytical grade and used as received.

Preparation of prepolyanhydride

Octadecanoic diacid prepolymer was prepared from the purified diacid monomer $(10 \mathrm{~g})$ by refluxing in the presence of excess acetic anhydride $(100 \mathrm{~mL})$ at $135^{\circ} \mathrm{C}$ for 40 min under nitrogen protection. Acetic acid and excess acetic anhydride were removed under vacuum at $50-60{ }^{\circ} \mathrm{C}$. The hot clear viscous residue was dissolved in $40 \mathrm{~mL}$ toluene, then cooled to $0{ }^{\circ} \mathrm{C}$ overnight and precipitated with $400 \mathrm{~mL}$ of a 1:1 mixture $(\mathrm{v} / \mathrm{v})$ of ethyl ether and petroleum ether. The white precipitate was collected by LD5-2A centrifuge (Beijing Medical Centrifuge Factory, Beijing, China), dried in vacuo at room temperature for $24 \mathrm{~h}$, and stored at $-20{ }^{\circ} \mathrm{C}$ until used.

\section{Preparation of POA}

The desired quantity of refined prepolymer was placed into the reactor in an oil bath at $180^{\circ} \mathrm{C}$, under vacuum for
$90 \mathrm{~min}$, to perform melt-polycondensation [15, 35]. The final product was dissolved into chloroform, and precipitated in cooled ethyl ether anhydrous. The precipitate was separated by filtration and washed with ethyl ether anhydrous for three times. Finally, POA was dried in vacuo at room temperature for $24 \mathrm{~h}$.

Poly(sebacic anhydride) (PSA) was also synthesized by the above method.

\section{Characterization of POA}

Fourier transform infrared spectroscopy (Nicolet MAGNAIR 560, Bio-Rad, United States) was used to confirm the structure of POA and its degradation products. The polymer samples were pressed into $\mathrm{KBr}$ pellets (1:100 copolymer/ $\mathrm{KBr}$ ratio) and analyzed with IR data manager software.

Wide angle X-ray diffraction patterns were recorded with graphite-filtered $\mathrm{CuK}_{\alpha}$ radiation produced with a BDX3300 diffractometer (Beijing university instrument manufacture, China). All the samples were measured under the voltage of $20 \mathrm{kV}$, the electrical current of $20 \mathrm{~mA}$, the scan range of $3^{\circ}-60^{\circ}$ and the scan interval of $0.02^{\circ}$.

Differential scanning calorimetry measurements were carried out with Diamond DSC (Perkin Elmer Co., USA). All the measurements were carried out at a heating (cooling) rate of $10{ }^{\circ} \mathrm{C} / \mathrm{min}$ from -50 to $200{ }^{\circ} \mathrm{C}$.

The microstructure of POA samples was investigated by scanning electron microscopy (SEM). For the SEM studies, the dried samples were fixed in a split specimen mount. After sputter-coated for several minutes with gold at room temperature, the samples were placed on a stage and observed by XL30 ESEM (PHILIPS).

In vitro degradation

The polyanhydride discs (200 $\mathrm{mg}$ in weight, $13 \mathrm{~mm}$ in diameter and $1.0 \mathrm{~mm}$ in thickness) were prepared by compression molding from the polyanhydride powder with 769YP-24B press (Tianjin KeQi New Technology Co, China) at $20 \mathrm{MPa}$ and room temperature for $5 \mathrm{~min}$. The degradation of polyanhydride discs was performed in $100 \mathrm{~mL}$ phosphate buffer $(\mathrm{pH} 5.98$ or 7.4) in incubator shaker (SHZ-88, Jintan Medical Treatment Instruments manufactory, Jiangsu, China) at $130 \mathrm{r} / \mathrm{min}$ and $37{ }^{\circ} \mathrm{C}$. The degradation medium was replaced by fresh phosphate buffer everyday. The erosion rate was measured by the change of dry weight and intrinsic viscosity ([ $\eta])$ of the polymer samples as shown in Formulae (1) and (2) [36, 37]. The $\mathrm{pH}$ value and conductivity value of the degradation medium were determined with $\mathrm{pH}$ meter (PHS-3C, Shanghai LeiCi Technology Co, China) and conductometer (DDS-312, Shanghai DaZhong Technology Co, China) at definite time intervals. 
$\mathrm{wt} \%=\frac{W_{0}-W}{W_{0}} \times 100 \%$

$[\eta]=\frac{\sqrt{2\left(\eta_{\mathrm{SP}}-\ln \eta_{r}\right)}}{C}$

where $W_{0}$ is the initial weight of the polyanhydride disc, $W$ is the weight of the polyanhydride disc after degradation, $\eta_{\mathrm{SP}}=\frac{t}{t_{0}}-1, \eta_{r}=\frac{t}{t_{0}}, t_{0}$ is the time that tetrahydrofuran solvent outflow Ubbelohde viscometer, $t$ is the time that polyanhydride solution outflow viscometer, and $C$ is the concentration of polyanhydride solution.

\section{Results and discussions}

Poly(octadecanoic anhydride) was synthesized by melt polycondensation. The reaction formulae are shown in Scheme 1.

In this reaction, octadecanoic diacid was firstly polymerized to form prepolymer of POA in the presence of acetic anhydride, and then prepolymer performed meltpolycondensation to form POA at $180{ }^{\circ} \mathrm{C}$ and high vacuum.

\section{Characterization of POA}

Figure 1 shows FTIR spectra of octadecanoic diacid, POA, and PSA. Comparing with the monomer (Curve A), in the FTIR spectrum (Curve B) of POA, the strong methylenecharacteristic bands appear at 2,919 and $2,851 \mathrm{~cm}^{-1}$, the strong anhydride bond-characteristic bands appear at 1,815 and $1,742 \mathrm{~cm}^{-1}$, the $\mathrm{C}-\mathrm{O}-\mathrm{C}$ stretching band appears at $1,101 \mathrm{~cm}^{-1}$. Disappearance of carboxylic hydroxyl band between 3,500 and $2,500 \mathrm{~cm}^{-1}$ and carboxylic carbonyl band at $1,701 \mathrm{~cm}^{-1}$ shows that all of carboxylic groups have changed into anhydride linkages. Comparing with the FTIR spectrum (Curve C) of PSA, the intensity of the methylene-characteristic bands is stronger, and those of the anhydride bond bands and the $\mathrm{C}-\mathrm{O}-\mathrm{C}$ band are weaker. It

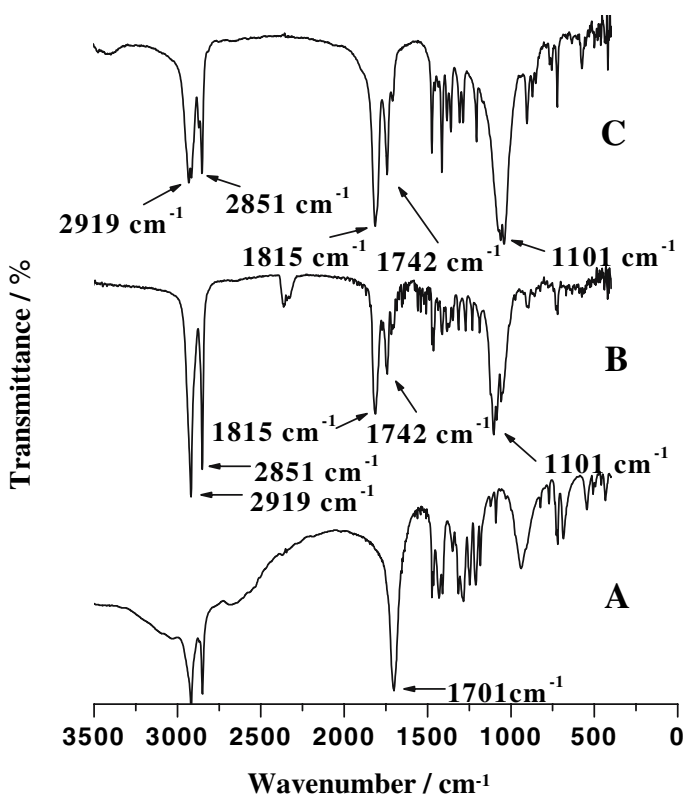

Fig. 1 FTIR spectra of octadecanoic diacid (A), POA (B) and PSA (C)

suggests that there are more methylene groups and less anhydride bonds in POA chain. This is consistent with its molecular structure.

The thermal properties of polyanhydrides, such as the melting point $\left(T_{\mathrm{m}}\right)$, crystallizing point $\left(T_{\mathrm{c}}\right)$, enthalpy of melting $\left(\Delta H_{\mathrm{m}}\right)$ and enthalpy of crystallizing $\left(\Delta H_{\mathrm{c}}\right)$, were determined by DSC, and the results were shown in Figs. 2, 3 , and Table 1. $T_{\mathrm{m}}$ during second run is higher than that of first run but $\Delta H_{\mathrm{m}}$ is opposite. It is well known that the crystal of polymers includes imperfect crystal and perfect crystal. At the first heating run, the non-perfect crystal recrystallized into perfect crystal, so polymers have wider range of melting process and higher enthalpy of melting. At the slow cooling run, the polymer crystal is more perfect because the crystalline temperature is higher. Comparing with the first heating run, the second heating run has higher melting temperature, narrower range of melting process and lower enthalpy of melting. It also can be seen from Figs. 2, 3, and Table 1 that $T_{\mathrm{c}}, T_{\mathrm{m}}, \Delta H_{\mathrm{c}}$, and $\Delta H_{\mathrm{m}}$ of POA
$\mathrm{R}(\mathrm{COOH})_{2}+2\left(\mathrm{CH}_{3} \mathrm{CO}\right)_{2} \mathrm{O} \longrightarrow \mathrm{CH}_{3} \mathrm{COOCORCOOCOCH}_{3}$

$+2 \mathrm{CH}_{3} \mathrm{COOH}$

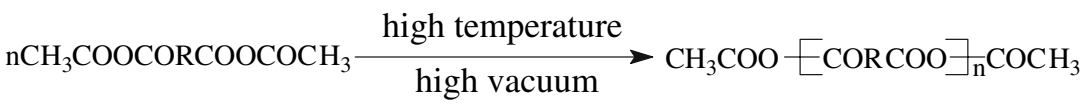

$$
\begin{aligned}
& +(\mathrm{n}-1)\left(\mathrm{CH}_{3} \mathrm{CO}\right)_{2} \mathrm{O} \\
& \mathrm{R}=\left(\mathrm{CH}_{2}\right)_{\mathrm{m}} \quad \mathrm{m}=16
\end{aligned}
$$



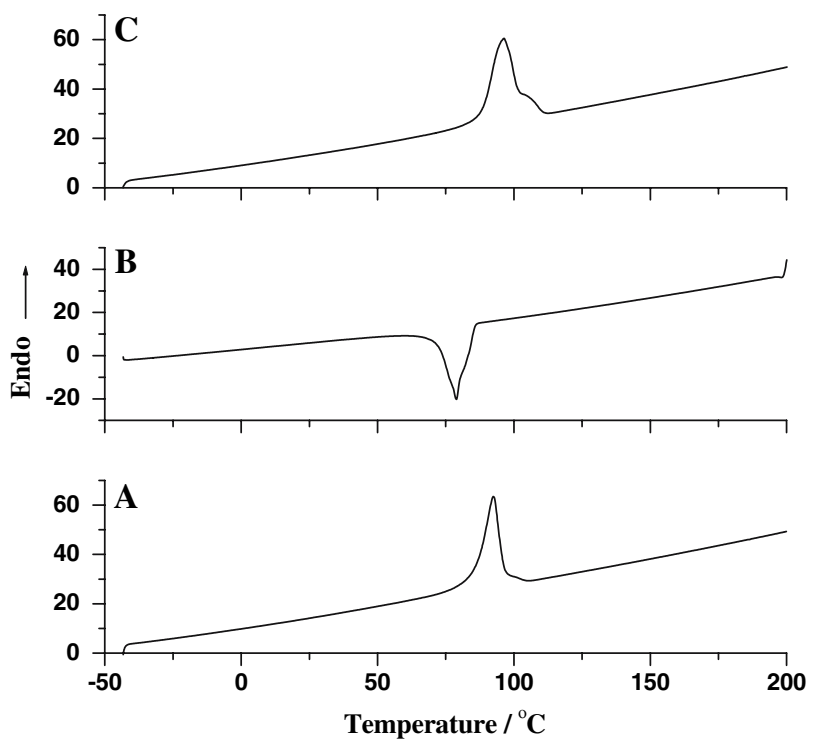

Fig. 2 DSC thermograms of POA. (A): First run; (B) cooled; (C) second run
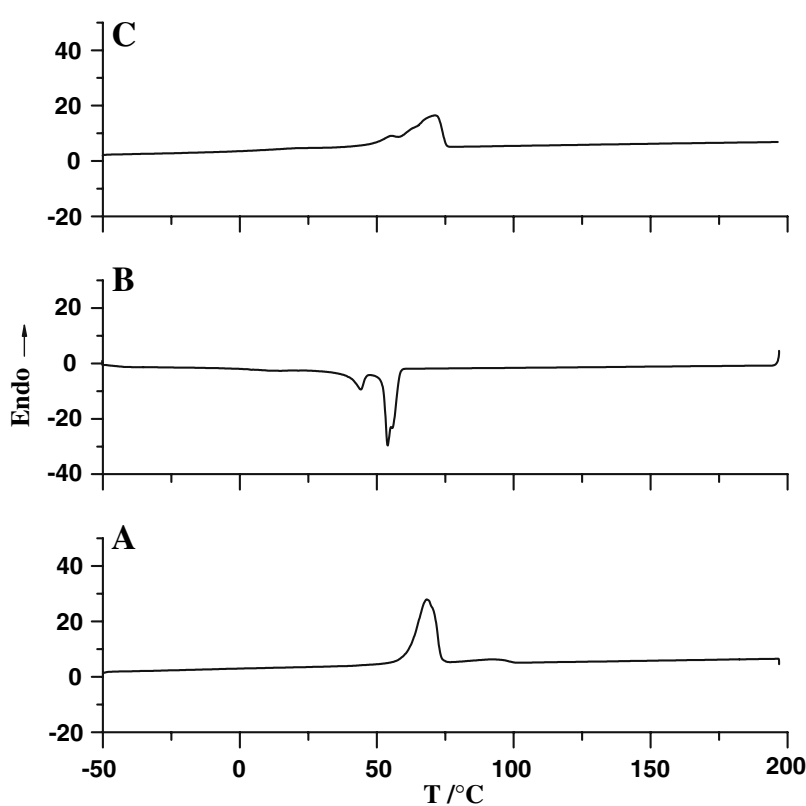

Fig. 3 DSC thermograms of PSA. (A) First run; (B) cooled; (C) second run are higher than those of PSA. This phenomenon suggests that the crystallization degree of POA is possibly higher than that of PSA.

Wide angle X-ray diffraction method was used to investigate the crystallizability of polyanhydrides and further validate the results of DSC. As shown in Fig. 4, the crystalline peaks of POA and PSA are almost at the same angles but the intensities of peaks are obviously different. PSA has four middle-intensity characteristic crystalline peaks at $2 \theta$ values of $19.4^{\circ}, 20.9^{\circ}, 23.2^{\circ}$, and $25.5^{\circ}$, and POA has a strong characteristic crystalline peak at $2 \theta$ value of $21.2^{\circ}$, a middle-intensity characteristic crystalline peak at $2 \theta$ value of $23.7^{\circ}$ and two weak characteristic crystalline peaks at $2 \theta$ values of $19.3^{\circ}$ and $25.1^{\circ}$. These indicate that there is an obvious change in the crystallization degree of POA. Flexibility and regulation of chain give rise to the change in the crystallization degree of POA. Therefore, the change in the crystallization degree is the reason why $T_{\mathrm{c}}, T_{\mathrm{m}}, \Delta H_{\mathrm{c}}$, and $\Delta H_{\mathrm{m}}$ of POA are higher than those of PSA.

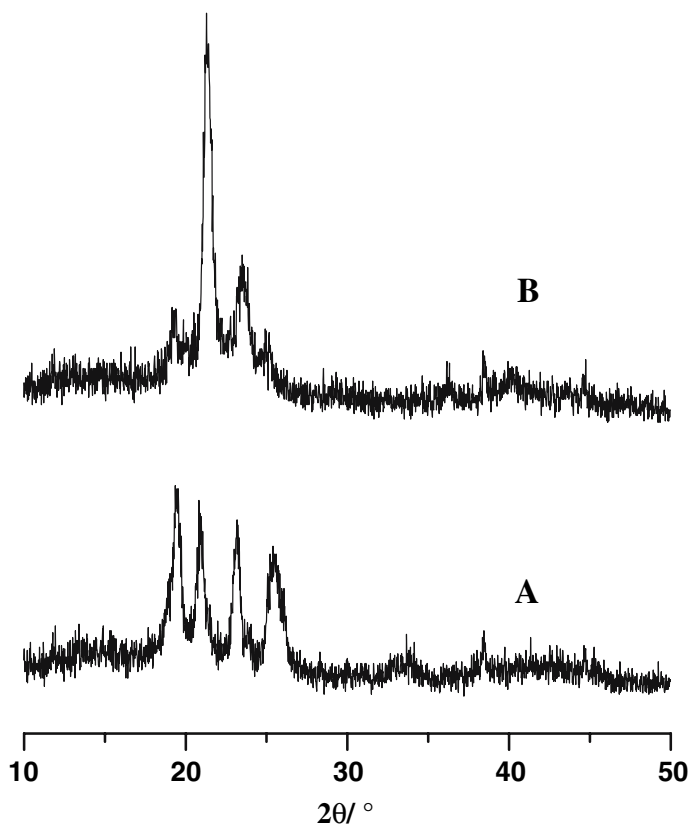

Fig. 4 Wide angle X-ray diffraction patterns of polyanhydrides. (A) PSA; (B) POA

Table 1 Results of DSC

\begin{tabular}{|c|c|c|c|c|c|c|}
\hline \multirow[t]{2}{*}{ Process } & \multicolumn{3}{|l|}{ POA } & \multicolumn{3}{|l|}{ PSA } \\
\hline & $T_{\mathrm{m}}\left({ }^{\circ} \mathrm{C}\right)$ & $T_{\mathrm{c}}\left({ }^{\circ} \mathrm{C}\right)$ & $\Delta H_{\mathrm{m}}(\mathrm{J} / \mathrm{g})$ & $T_{\mathrm{m}}\left({ }^{\circ} \mathrm{C}\right)$ & $T_{\mathrm{c}}\left({ }^{\circ} \mathrm{C}\right)$ & $\Delta H_{\mathrm{m}}(\mathrm{J} / \mathrm{g})$ \\
\hline First run & 92.2 & - & 175.5 & 68.4 & - & 116.7 \\
\hline Cooled & - & 79.1 & -138.9 & - & 54 & -100.8 \\
\hline Second run & 96.3 & - & 138.3 & 71.4 & - & 101.3 \\
\hline
\end{tabular}




\section{Degradation}

Degradation is an important character for biomaterials. In this article, in vitro degradation of synthesized polyanhydride in phosphate buffers at $37{ }^{\circ} \mathrm{C}$ was evaluated.

In order to understand degradation of POA, $\mathrm{pH}$ and conductivity values of the degradation medium $(\mathrm{pH} 5.98$ PBS) were determined by $\mathrm{pH}$ meter and conductometer. In these experiments, the degradation medium was not replaced by fresh phosphate buffer. As shown in Table 2, the $\mathrm{pH}$ value of the degradation medium decreases with POA degradation carrying out and then tends to level off. The conductivity of the degradation medium increases from 1.1 to $4.9 \mu \mathrm{s}$ after $24 \mathrm{~h}$ and then slowly increases to $6.8 \mu \mathrm{s}$ after 4 days. In contrast with POA, the conductivity value of the degradation medium of PSA experiences a rapidly increase in the first day from 1.1 to $31.8 \mu$ s and then increases gradually. All of these suggest that POA, acting as PSA, degrades into diacid counterparts, but the degradation rate is lower than that of PSA.

FTIR spectra of POA before and after degradation are shown in Fig. 5. After degradation, the wavenumbers of characteristic bands of POA, such as methylene-characteristic bands, anhydride bond-characteristic bands, $\mathrm{C}-\mathrm{O}-\mathrm{C}$ stretching band, hardly change. However, the strong carboxylic hydroxyl band between 3,500 and $2,500 \mathrm{~cm}^{-1}$ and the strong carboxylic carbonyl band at $1,701 \mathrm{~cm}^{-1}$ appear and become stronger with increasing the degradation time. The intensities of the anhydride bond-characteristic bands at 1,815 and $1,742 \mathrm{~cm}^{-1}$ and the $\mathrm{C}-\mathrm{O}-\mathrm{C}$ stretching band at $1,101 \mathrm{~cm}^{-1}$ obviously become weaker. The above phenomena illuminate that the content of carboxylic groups in POA sample gradually increases and the number of anhydride bonds is opposite in the degradation process.

The hydrolytic degradations of polyanhydrides were performed in $100 \mathrm{~mL}$ phosphate buffer at pH 5.98 and 7.4, respectively and the degradation medium was replaced with fresh phosphate buffer everyday. The degradation rate was determined by weight loss of the polymers in the

Table $2 \mathrm{pH}$ value and conductance value of degradation medium

\begin{tabular}{|c|c|c|c|c|}
\hline \multirow[t]{2}{*}{ Degradation time/day } & \multicolumn{2}{|c|}{$\mathrm{pH}$ value } & \multicolumn{2}{|c|}{ Conductance value $/ \mu \mathrm{s}$} \\
\hline & POA & PSA & POA & PSA \\
\hline 0 & 5.98 & 5.98 & 1.1 & 1.1 \\
\hline 1 & 5.17 & 3.93 & 4.9 & 31.8 \\
\hline 2 & 5.10 & 3.83 & 6.4 & 39.2 \\
\hline 3 & 5.09 & 3.80 & 6.6 & 43.3 \\
\hline 4 & 5.10 & 3.79 & 6.8 & 45.8 \\
\hline
\end{tabular}

Note: $\mathrm{pH} 5.98$ phosphate buffer was used as degradation medium and the dissolution fluid was not replaced by fresh phosphate buffer during this degradation experiment

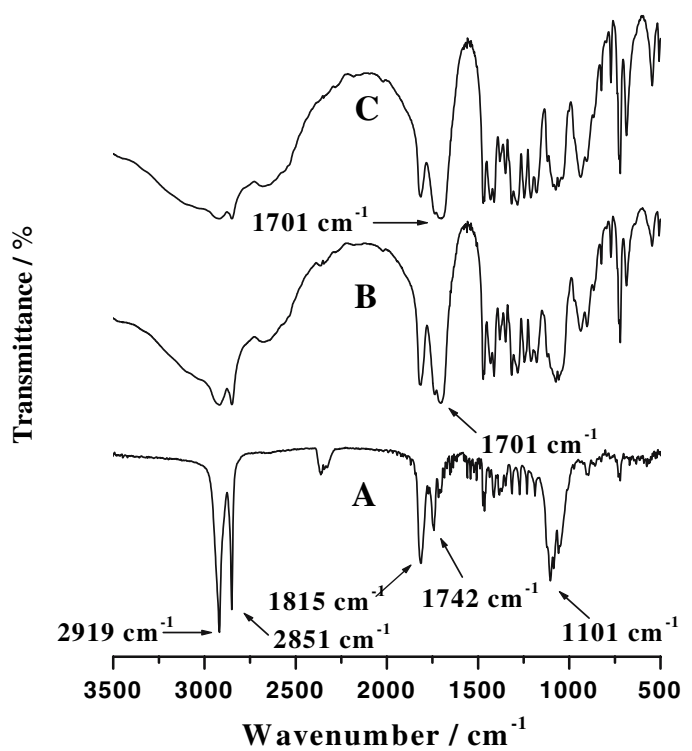

Fig. 5 FTIR spectra of POA degrading in phosphate buffer with $\mathrm{pH}$ value of 5.98. (A) POA; (B) after 5 days degradation; (C) after 15 days degradation

degradation process. The results are shown in Figs. 6 and 7. The linearity of weight loss to hydrolytic degradation time suggests that POA undergoes surface front erosion.

As seen from Figs. 6 and 7, whether acidic condition or basic condition, the degradation rate of POA is far slower than that of PSA. Under the acidic condition, the weight loss of POA is only $1.64 \%$ after 20 days degradation, but that of PSA is higher than $57 \%$. Under the basic condition, PSA completely hydrolyzes in 3 days, while POA needs 18 days. These phenomena indicate that the degradation rate of POA is lower than that of PSA. Mathiowitz et al. [38] introduced that the degree of crystallinity of polyanhydride may play an important role in preventing diffusion of water

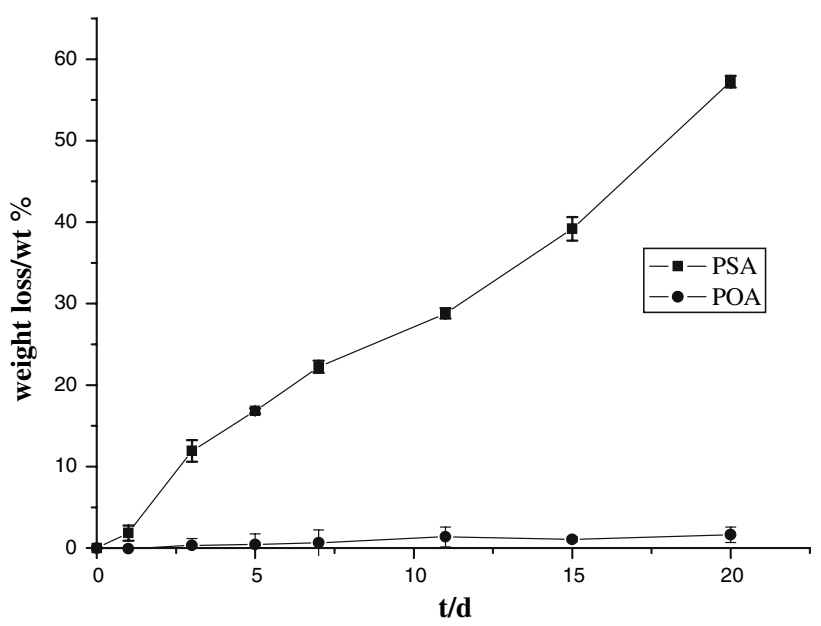

Fig. 6 Weight loss of polyanhydride during the degradation in phosphate buffer ( $\mathrm{pH}$ 5.98) 


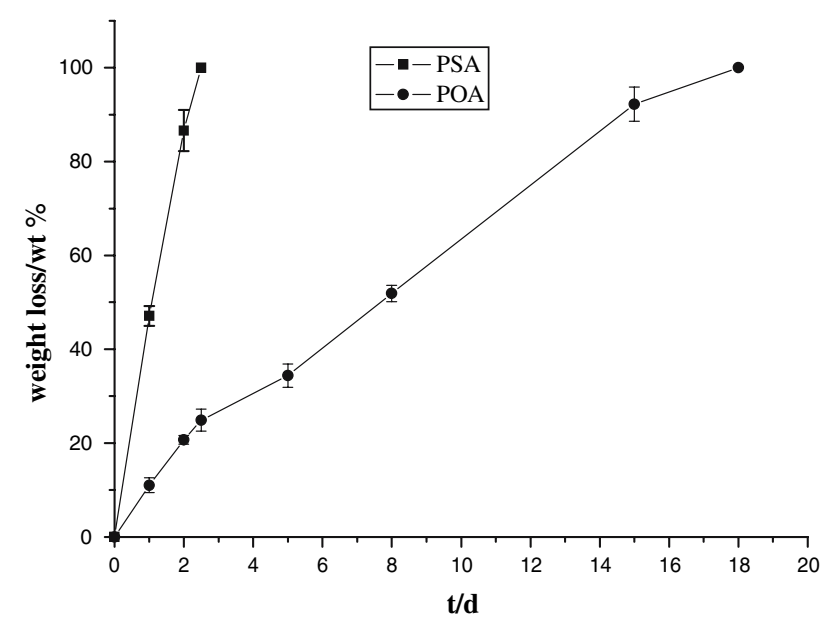

Fig. 7 Weight loss of polyanhydride during the degradation in phosphate buffer ( $\mathrm{pH} 7.4)$

into the polymer bulk and thus preventing bulk erosion. As the results of WAXD and DSC, the crystallization degree of POA is higher than that of PSA, and the higher crystallization degree slows the hydrolytic rate of POA.

The degradation rate of POA under basic condition is far-forth higher than that of acidic condition. This may be relative to the properties of the anhydrides linkages, the hydrolysis of anhydride bond is basic catalyzed and hence is significantly faster in basic condition than in acidic condition. In acidic medium, the hydrolysis is slow to begin with and the polyanhydrides degrade to diacids, which hardly dissolve in acidic buffer. But the degradation products can be ionized under the basic condition, which enhances the hydrophilicity and diffusion of the degradation products. Therefore, POA degrades quickly under the basic condition.

In order to investigate the change of the molecular weight of polyanhydrides during the degradation process, the intrinsic viscosity $([\eta])$ of the polymer samples was measured by Ubbelohde viscometer. As shown in Fig. 8, $[\eta]$ of polyanhydrides obviously decreases at the first 3 days and then level off. It indicates that the degradation of polyanhydrides obeys the surface-erosion mechanism, only the surface anhydride linkages break and the molecular weight of the inner polymer hardly changes.

In order to see how the microstructure changes during erosion, the outer surface and cross section of POA samples before and after erosion were observed by SEM. Figure 9 shows the polymer matrix surface before and after erosion. After 3 days erosion, the smooth surface (Fig. 9A) of the POA sample becomes rougher. There are a few of pores on the sample surface under the acidic condition (PBS, pH 5.98) as shown in Fig. 9B. But the sample under the basic condition (PBS, $\mathrm{pH}$ 7.4) is of much highly porous surface as shown in Fig. 9C. Figure 10 shows the cross

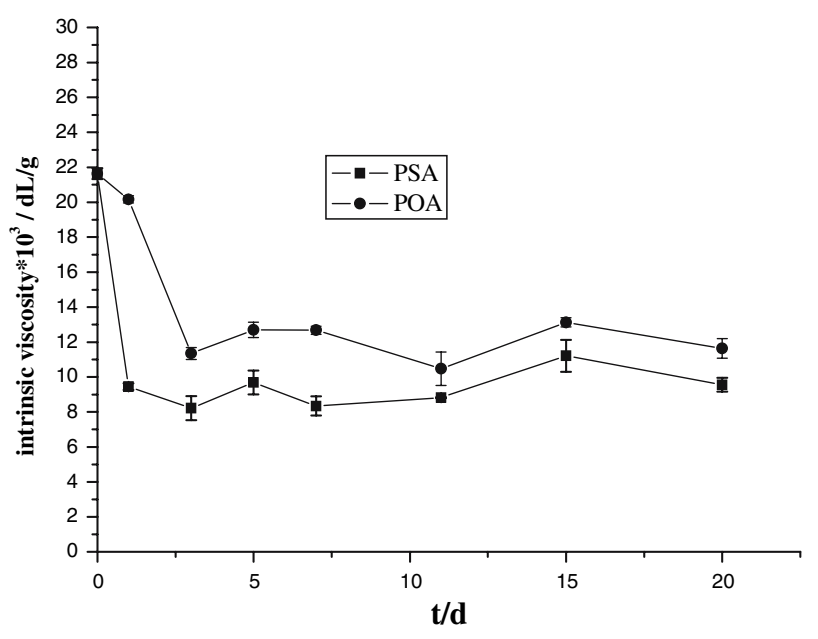

Fig. 8 Change of $[\eta]$ of polyanhydride samples during the degradation process

section of eroded POA sample after 3 days. The cross section of eroded POA sample under the acidic condition (PBS, pH 5.98) is smooth as shown in Fig. 10A, which suggests that the surface of the POA sample is lightly eroded and the interior is not eroded by the buffer. Similar to the investigation of Langer colleagues [39], the cross section of eroded POA samples is composed of three different layers as sandwich under the basic condition (PBS, $\mathrm{pH}$ 7.4). Two outer layers where the polymer has already been eroded the buffer are shown in Fig. 10C and the inner layer where the polymer is not eroded is shown in Fig. 10B. Figure 10C shows that the outer eroded layers consist of loosely associated polymer plates, which are separated by pores of size in the range of $0.05-1 \mu \mathrm{m}$. It is obvious that the polymer has changed from non-porous bulk into highly porous material due to the faster erosion in amorphous parts than that in crystalline parts. The above phenomena indicate that the erosion process is neither bulk nor perfect surface erosion but rather has elements of both. The moving erosion front is characteristic of surface erosion whereas the remaining porous shell stems from bulk erosion.

\section{Conclusion}

Poly(octadecanoic anhydride) has been synthesized by melt polycondensation. The results of FTIR show that all the carboxyl groups change into anhydride bonds. Comparing with PSA, POA has an obviously higher crystallization degree with higher $T_{\mathrm{m}}, T_{\mathrm{c}}, \Delta H_{\mathrm{m}}$, and $\Delta H_{\mathrm{c}}$.

Poly(octadecanoic anhydride) is a hydrophobic polymer joined with more readily hydrolytic anhydride linkages, which can hydrolyzes into diacid counterparts. The erosion process of POA is of both bulk and surface erosion 

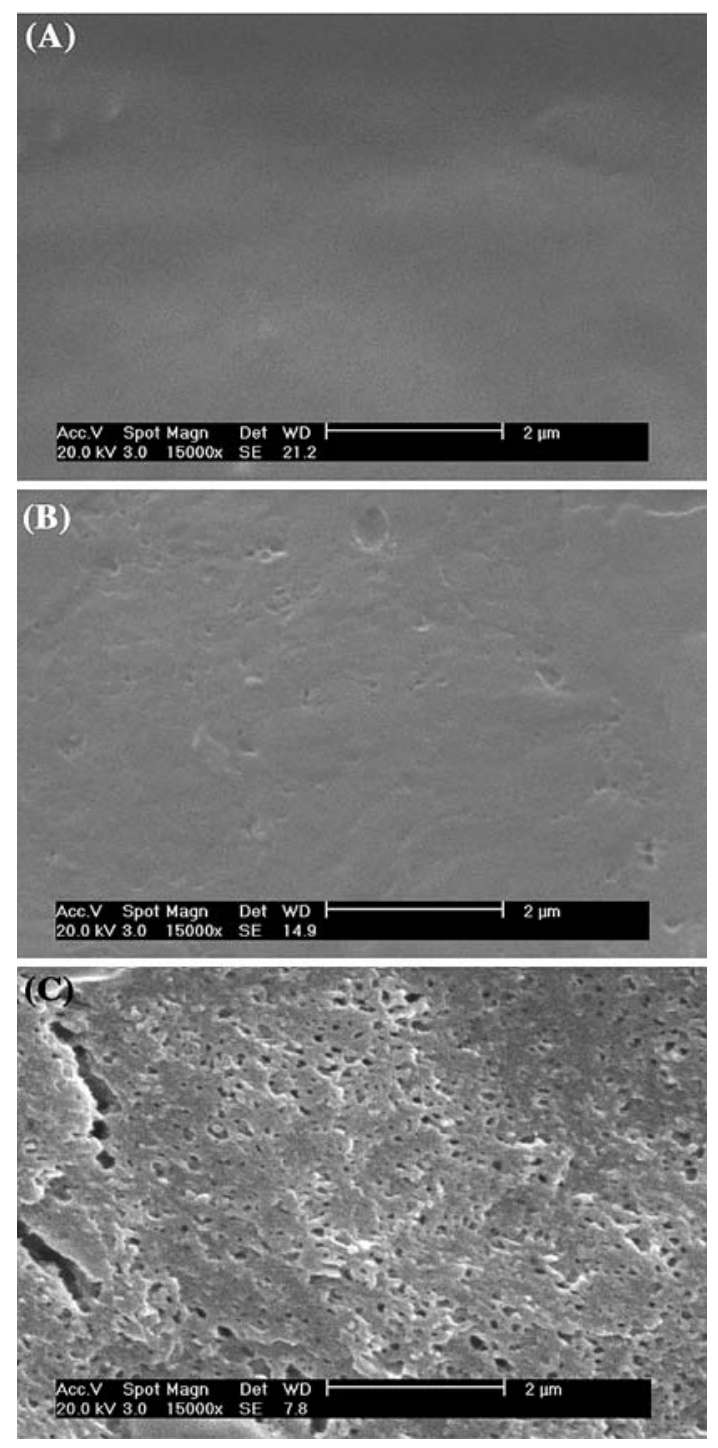

Fig. 9 SEM micrographs of the outer surface of POA discs before (A) and after 3 days erosion in PBS buffer, $\mathrm{pH} 5.98$ (B) and $\mathrm{pH}=7.4$ (C) $($ Scale bar $=2 \mu \mathrm{m})$

mechanism. The molecular weight is basically invariable during the erosion process. The degradation rate of POA depends the $\mathrm{pH}$ value of the phosphate buffer. The POA only loses its $1.64 \mathrm{wt} \%$ after 20 days degradation in PBS (pH 5.98), but completely degrades after 18 days in PBS ( $\mathrm{pH} 7.4)$.

Poly(octadecanoic anhydride) with excellent degradability likely becomes a useful short-term medical biomaterial. In order to obtain a novel biomaterial with excellent properties, POA may also copolymerize or blend with other polymers. In our laboratory, the copolymers have been prepared from POA and PSA. Comparing with PSA, the degradability of the copolymers is markedly controlled, so POA can promote the further application of PSA in drug controlled release system.
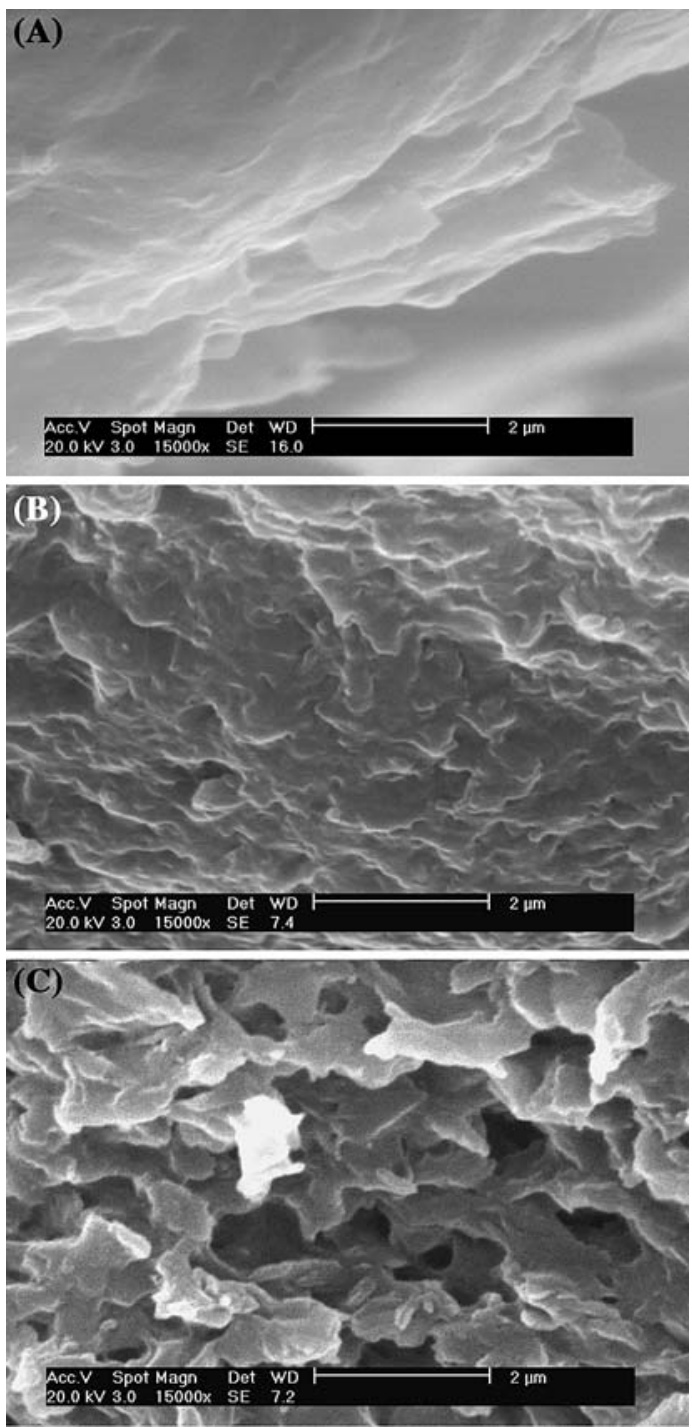

Fig. 10 SEM micrographs of the cross section of eroded POA discs after 3 days erosion in PBS buffer, $\mathrm{pH} 5.98$ (A) and $\mathrm{pH}=7.4$ (B and C) $($ Scale bar $=2 \mu \mathrm{m})$

Acknowledgements This work had been supported by Program for New Century Excellent Talents in University of China, the National Natural Science foundation of China (project 30170227) and the open foundation of State Key Laboratory of Biomembrane and Membrane Biotechnology of China.

\section{References}

1. D. S. KATTI, S. LAKSHMI, R. LANGER and C. T. LAURENCIN, Adv. Drug Delivery Rev. 54 (2002) 933

2. N. KUMAR, M. N. V. RAVIKUMAR and A. J. DOMB, $A d v$. Drug Delivery Rev. 53 (2001) 23

3. F. V. BURKERSRODA, L. SCHEDL and A. GÖPFERICH, Biomaterials 23 (2002) 4221

4. K. E. UHRICH, S. M. CANNIZZARO, R. S. LANGER and K. M. SHAKESHEFF, Chem. Rev. 99 (1999) 3181 
5. A. GÖPFERICH and J. TESSMAR, Adv. Drug Delivery Rev. 54 (2002) 911

6. X. H. CHEN and J. H. ZHENG, Polym. Mater. Sci. Eng. 19(3) (2003) 31

7. H. B. ROSEN, J. CHANG, G. E. WNEK, R. J. LINHARDT and R. LANGER, Biomaterials 4 (1983) 131

8. N. KUMAR, M. KRISHNAN, T. AZZAM, A. MAGORA, M. N.V. RAVIKUMAR, D. R. FLANAGAN and A. J. DOMB, Anal. Chim. Acta. 465 (2002) 257

9. N. KUMAR, R. S. LANGER and A. J. DOMB, Adv. Drug Delivery Rev. 54 (2002) 889

10. K. S. ANSETH and D. J. QUICK, Macromol. Rapid Commun. 22 (2001) 564

11. A. K. BURKOTH and K. S. ANSETH, Biomaterials 21 (2000) 2395

12. R. C. SCHMELTZER, K. E. SCHMALENBERG and K. E. UHRICH, Biomacromolecules 6 (2005) 359

13. B. A. PFEIFE, J. A. BURDICK and R. LANGER, Biomaterials 26 (2005) 117

14. M. Y. KRASKO, A. SHIKANOV, A. EZRA and A. J. DOMB, $J$. Polym. Sci. A Polym. Chem. 41 (2003) 1059

15. CH. K. CHAN and I. M. CHU, Biomaterials 24 (2003) 47

16. J. WANG, L. X. CHEN and J. FU, Mater. Sci. Ed. 16(3) (2001) 49

17. A. J. DOMB, C. F. GALLARDO and R. LANGER, Macromolecules 22 (1989) 3200

18. Q.X. CAI, K. J. ZHU, D. CHEN and L. P. GAO, Eur. J. Pharm. Biopharm. 55 (2003) 203

19. T. J. ANASTASIOU and K E. UHRICH, J. Polym. Sci. A Polym. Chem. 41 (2003) 3667

20. D. T. T. YAPP, D. K. LLOYD, J ZHU and S LEHNERT, Radiother. Oncol. 53 (1999) 77

21. E. SHEN, M. J. KIPPER, B. DZIADUL, M. K. LIM and B. NARASIMHAN, J. Control Release 82 (2002) 115

22. M. J. KIPPER, E. SHEN, A. DETERMAN and B. NARASIMHAN, Biomaterials 23 (2002) 4405
23. D. STEPHENS, L. LI, D. ROBINSON, S. CHEN, H. CH. CHANG, R. M LIU, Y. Q. TIAN, E. J. GINSBURG, X. Y. GAO and T. STULTZ, J Control Release 63 (2000) 305

24. E. S. Park, M. MANIAR and J. C. SHAH, J. Control Release 52 (1998) 179

25. C. A. SANTOS, B. D. FREEDMAN, K. J. LEACH, D. L. PRESS, M. SCARPULLA and E. MATHIOWITZ, J. Control Release 60 (1999) 11

26. M. SANDOR, N. A. Bailey and E. MATHIOWITZ, Polymer 43 (2002) 279

27. W. B. DANG, T. DAVIAU and H. BREM, Pharm. Res. 13 (1996) 683

28. A. J. DOMB, Z. H. ISRAEL, O. ELMALAK, D. TEOMIM and A. BENTOLILA, Pharm. Res. 16(5) (1999) 762

29. W. VOGELHUBER, T. SPRUß, G. BERNHARDT, A. BUSCHAUER and A. GÖPFERICH, Int. J. Pharm. 238 (2002) 111

30. J. P. JAIN, S. MODI, A. J. DOMB, N. KUMAR, J. Control Release 103 (2005) 541

31. L. Ch. LI, J. DENG and D. STEPHENS, Adv. Drug Delivery Rev. 54 (2002) 963

32. D. J. QUICK, K. K. MACDONALD and K. S. ANSETH, $J$. Control Release 97 (2004) 333

33. H. L. JIANG and K. J. ZHU, Int. J. Pharm. 194(1) (2000) 51

34. B. M. VOGEL and S. K. MALLAPRAGAD, Biomaterials 26 (2005) 721

35. A. J. DOMB and R. J. LANGER, Polym. Sci. A Polym. 25 (1987) 3373

36. A-A. A. ABDEL-AZIM, A. M. ATTA, M. S. FARAHAT and W. Y. BOUTROS, Polymer 39 (1998) 6827

37. O. F. SOLOMON and I. Z. CIUTA, J. Appl. Polym. Sci. 6(1962) 683

38. E. MATHIOWITZ, E. RON and G. MATHIOWITZ, Macromolecules 23 (1990) 3212

39. A. GÖPFERICH and R. J. LANGER, Polym. Sci. A Polym. Chem. 31 (1993) 2445 